Louisiana State University

LSU Digital Commons

3-1-2006

\title{
Comparative phylogeography in a genus of coral reef fishes: Biogeographic and genetic concordance in the Caribbean
}

\author{
Michael S. Taylor \\ Louisiana State University \\ Michael E. Hellberg \\ Louisiana State University
}

Follow this and additional works at: https://digitalcommons.Isu.edu/biosci_pubs

\section{Recommended Citation}

Taylor, M., \& Hellberg, M. (2006). Comparative phylogeography in a genus of coral reef fishes: Biogeographic and genetic concordance in the Caribbean. Molecular Ecology, 15 (3), 695-707. https://doi.org/10.1111/j.1365-294X.2006.02820.x 


\title{
Comparative phylogeography in a genus of coral reef fishes: biogeographic and genetic concordance in the Caribbean
}

\author{
MICHAEL S. TAYLOR and MICHAEL E. HELLBERG \\ Department of Biological Sciences, Louisiana State University, Baton Rouge, Louisiana 70803, USA
}

\begin{abstract}
Geographic barriers that limit the movement of individuals between populations may create or maintain phylogenetically discrete lineages. Such barriers are often inferred from geographic surveys of a single mitochondrial marker to identify phylogenetic splits. Mitochondrial DNA, however, has an effective population size one-fourth that of nuclear DNA, which can facilitate the rapid evolution of monophyletic mtDNA lineages in the absence of geographic barriers. The identification of geographic barriers will thus be more robust if barriers are proposed a priori, and tested with multiple independent genetic markers in multiple species. Here, we tested two proposed marine biogeographic breaks located at the Mona Passage in the Caribbean Sea and at the southern end of Exuma Sound in the Bahamas. We sequenced mitochondrial cytochrome $b(400 \mathrm{bp}$ ) and nuclear rag1 (573 bp) for nine species and colour forms (183 individuals total) within the teleost genus Elacatinus (Gobiidae) that span the proposed breaks. Our results showed that Mona Passage separated $m t c y b$ and rag1 lineages, with no genetic exchange between populations separated by just $23 \mathrm{~km}$. However, the Central Bahamas barrier was only weakly supported by our data. Importantly, neither barrier coincided with deep genetic splits. This suggests that these two barriers did not initially isolate regional populations, but instead disrupt ongoing gene flow between regions. Our inferred relationships further suggested a division of the Caribbean region into northwestern and southeastern regions, a pattern reflected by some freshwater and terrestrial vertebrates. Our results, coupled with genetic and demographic data from other reef fishes and corals, provide robust support for the Mona Passage as a long-term biogeographic barrier for Caribbean animals.
\end{abstract}

Keywords: biogeographic barriers, Caribbean fishes, comparative phylogeography

Received 20 July 2005; revision accepted 31 October 2005

\section{Introduction}

Geographic barriers that limit the movement of individuals between populations may lead to the evolution of phylogenetically discrete lineages, or maintain differences between parapatric lineages at range boundaries. Populations that remain genetically distinct over evolutionary timescales may give rise to new species. Thus, a critical step towards understanding patterns of geographic speciation is the identification of barriers to dispersal (Avise 2000; Wiens 2004).

Correspondence: Michael S. Taylor, Present address: Department of Biological Sciences, 107 Galvin Life Sciences Bldg, University of Notre Dame, Notre Dame, Indiana 46556, USA. Fax: (574) 6317413; E-mail: mtaylor9@nd.edu
Many geographic barriers, such as mountains or desert expanses, are readily apparent; however, barriers in the ocean are generally less obvious. The lack of obvious oceanic barriers is especially acute in geographically compact regions such as the Caribbean Sea. This region harbours a diverse array of species (Briggs 1974; Robertson 1998) and several endemic radiations (e.g. Domeier 1994; Hastings 2000; Williams \& Mounts 2003; Morrison et al. 2004) despite the potential for pelagic larvae to disperse long distances on Caribbean currents (Shulman \& Bermingham 1995). Thus, the processes underlying the geographic origins of high biodiversity in this region remain enigmatic.

Increasingly, biogeographic history is studied with the aid of molecular phylogeographic analyses (Avise 2000; Barraclough \& Vogler 2000). Biogeographic breaks may be inferred post hoc by the observation of large genetic gaps 
between neighbouring populations or cryptic sister species (Irwin 2002). Most commonly, the genetic markers employed in such phylogeographic studies are from mitochondrial DNA (mtDNA). Mitochondrial DNA, however, has an effective population size that is four times smaller than autosomal nuclear DNA (Birky et al. 1983, 1989). This property of mtDNA can lead to the random and comparatively rapid evolution of deep phylogenetic splits between lineages that are continuously distributed, especially for species that have small population size or low dispersal distance (Neigel \& Avise 1993; Irwin 2002). The observation of a single deep division between mtDNA lineages may lead to the incorrect inference of a barrier to gene flow (Neigel \& Avise 1993; Irwin 2002). Thus, caution is required when proposing previously unrecognized biogeographic barriers based on mtDNA alone. Conclusions drawn from phylogeographic studies will be more robust if (i) phylogenies derived from independently segregating genetic markers are concordant, (ii) phylogenies obtained for multiple taxa are concordant, and (iii) the location of barriers are proposed a priori (Neigel \& Avise 1993; Irwin 2002).

Few barriers have been proposed within the marine region that encompasses the Caribbean Sea, the Bahama Islands, and the lower Floridian peninsula. This mostly tropical region spans from a region of upwelling near Cape Canaveral, Florida, south to the copious freshwater outflows of the Amazon and Orinoco rivers (Briggs 1974; Avise 2000). These delimiting boundaries coincide with distinct biogeographic break points (Avise 2000; Rocha 2003) and encompass broad faunal homogeneity, which suggests that the Caribbean region (in the broad sense) is a natural biogeographic province. Briggs (1974), however, recognized two provinces within this region: a coastal Caribbean Province (including peninsular Florida) and an insular West Indies Province (including the Bahamas and Bermuda). That Florida has many faunal differences from the remainder of the Caribbean region has been long recognized (e.g. Mayr 1954; Böhlke \& Robins 1960; Böhlke \& Springer 1961). However, the distinction between insular and coastal provinces (excluding Florida) may be unwarranted due to considerable faunal similarity between them (Greenfield 1979; Acero P. 1985).

Despite the ubiquity of many species across the Caribbean region, the presence of regional endemism (e.g. Böhlke \& Robins 1968; Collette 1974; Johnson \& Brothers 1989) and restricted distributions (e.g. Starck \& Colin 1978; Domeier 1994) of some species suggests that biogeographic breaks may be present. One break has been inferred for the central Bahamas near Long Island, due to past isolation of the deep waters of Exuma Sound and the Tongue of the Ocean (Colin 1975) and potential for larval retention based on current flow in this area (Colin 1995). A second break may be present at Mona Passage between Puerto Rico and Hispaniola, because some reef fishes have distributions restricted to the west of Mona Passage (Colin et al. 2003; Dennis et al. 2004), although a mechanism to explain how the passage might serve as a barrier has not yet been proposed (see Discussion).

Genetic data supporting these biogeographic breaks have been lacking. Recently, however, we (Taylor \& Hellberg 2003) found strong genetic structure in a Caribbean reef fish, Elacatinus evelynae, based on mitochondrial cytochrome $b$ sequence. Genetic differentiation coincided with the two proposed biogeographic breaks. Further, these breaks separated the three recognized colour forms of E. evelynae (Colin 1975), which suggested that these locations may be barriers to gene flow or determine the range limits of the individual colour forms. Other Elacatinus species show distributions similar to that of E. evelynae (Colin 1975). Thus, the Mona Passage and Central Bahamas barriers may be common factors underlying geographic speciation or constraining the distribution of these gobies.

Here, we tested whether these two proposed Caribbean biogeographic barriers separated discrete genetic lineages within two ecologically distinct clades of the genus Elacatinus (Gobiidae) that encompass the central Bahamas and the Mona Passage. For each taxon, we sequenced one mitochondrial and one nuclear marker. Our results strongly supported the presence of a biogeographic break at the Mona Passage, with weaker support for a break in the central Bahamas.

\section{Materials and methods}

Species of Elacatinus with distributions encompassing Mona Passage and the central Bahamas include a cleaner goby (Elacatinus evelynae) that removes parasites from other fishes, and a complex of sponge-dwellers (Elacatinus chancei, Elacatinus horsti, Elacatinus lori, Elacatinus louisae) that live primarily in tube sponges (Colin 1975). These species were chosen to represent the two major ecological radiations in this subgenus because different habitat preferences may affect their ability to transgress biogeographic barriers (Rocha et al. 2002). Within the sponge-dwellers, E. lori, which is restricted to the Gulf of Honduras (Colin 2002), may be more closely related to E. horsti from the Bahamas than to the geographically closer populations of E. horst $i$ from Jamaica or Grand Cayman (Taylor \& Hellberg 2005). To explore this possible phylogeographic connection between the Gulf of Honduras and the Bahamas in greater detail, we included Elacatinus oceanops, a cleaner goby that has a disjunct distribution between the Gulf of Honduras and Florida, in our analysis of E. evelynae. Our previous work (Taylor \& Hellberg 2005) suggested that E. oceanops is closely related to yellow form E. evelynae from the northern Bahamas.

For each species, we sampled 1-10 individuals (mode $=8$ ) from populations that delimit the full extent of their 
Table 1 Number of individuals $(N)$ and unique haplotypes for each genetic marker for each taxon and island population

\begin{tabular}{|c|c|c|c|}
\hline Species & $N$ & $m t c y b$ & rag1* \\
\hline \multicolumn{4}{|l|}{ Cleaners } \\
\hline E. oceanops & 20 & 11 & 12 \\
\hline Belize & 10 & & \\
\hline Florida Keys & 10 & & \\
\hline E. evelynae & 80 & 44 & 77 \\
\hline Blue form & 40 & 17 & 44 \\
\hline San Salvador & 8 & & \\
\hline Grand Turk & 8 & & \\
\hline Puerto Rico & 8 & & \\
\hline Barbados & 8 & & \\
\hline Curaçao & 8 & & \\
\hline White form & 24 & 17 & 27 \\
\hline Isla Desecheo & 8 & & \\
\hline Jamaica & 8 & & \\
\hline Grand Cayman & 8 & & \\
\hline Yellow form & 16 & 10 & 23 \\
\hline Long Island & 8 & & \\
\hline N. Bahamast & 8 & & \\
\hline \multicolumn{4}{|l|}{ Sponge-dwellers } \\
\hline E. chancei & 24 & 5 & 11 \\
\hline Grand Turk & 8 & & \\
\hline Puerto Rico & 8 & & \\
\hline Barbados & 8 & & \\
\hline E. horsti & 32 & 13 & 15 \\
\hline White form & 8 & 5 & 6 \\
\hline Jamaica & 8 & & \\
\hline Yellow form & 24 & 8 & 9 \\
\hline N. Bahamas & 7 & & \\
\hline San Salvador & 1 & & \\
\hline Grand Cayman & 8 & & \\
\hline Curaçao & 8 & & \\
\hline E. lori & 9 & 2 & 1 \\
\hline Belize & 9 & & \\
\hline E. louisae & 18 & 6 & 12 \\
\hline N. Bahamas & 4 & & \\
\hline San Salvador & 1 & & \\
\hline Grand Turk & 8 & & \\
\hline Jamaica & 1 & & \\
\hline Grand Cayman & 4 & & \\
\hline
\end{tabular}

*Six individuals for which rag1 allele phase could not be determined are not included.

tN. Bahamas includes two individuals from each of Eleuthera, Cat and Lee Stocking islands, and Sweetings Cay.

respective distributions across the Caribbean region, which includes representatives of colour forms (cf. Colin 1975) for species that are otherwise morphologically indistinguishable (Fig. 1). In all, 100 cleaner and 83 spongedweller individuals were analysed. We considered each of the two proposed barriers independently because they did not have a common geological history (Malfait \& Dinkelman 1972; Pindell \& Barrett 1990) and were unlikely to have imparted a common phylogeographic signature among species with distributions that encompass both barriers.

\section{DNA amplification}

Total genomic DNA was extracted from muscle tissue with a QIAGEN DNA Mini Kit following the manufacturer's instructions. Polymerase chain reaction (PCR) was used to amplify protein-encoding regions of two genetic markers: mitochondrial cytochrome $b(m t c y b)$ and nuclear recombination-activating gene 1 ( rag1). The marker $m t c y b$ was amplified with primers GLUDG-5' and CB2-3' (Palumbi 1996), and TgrH15153 (5'-GCWCCTCARAARGAYATTTGTCC-3') designed for this study. The marker rag1 was amplified with primers rag1F623 (5'-GTTTGCACTCTCTGTGACACCAC3'), rag1F626 (5'-TTGCACTCTCTGTGACACCACTCG-3'), rag1R1221 (5'-CARGGTCTTGTGGAGGTAATTGGTT-3') and rag1R (5'-GACTCATTCCCCTCGCTGGC-3'), derived from rag1 sequences obtained from a phylogenetic study of the genus (Taylor \& Hellberg 2005).

PCR was performed on a PTC-200 (MJ Research) with the following conditions: $94{ }^{\circ} \mathrm{C}$ for $3 \mathrm{~min}$ for initial denaturing, followed by 35 cycles of $94^{\circ} \mathrm{C}$ for $15 \mathrm{~s}, 48-58^{\circ} \mathrm{C}$ for $20 \mathrm{~s}$, and $72{ }^{\circ} \mathrm{C}$ for $30-60 \mathrm{~s}$, depending on the primers used. Resulting amplicons were purified with a Strataprep PCR Purification Kit (Stratagene), then sequenced in both directions on an ABI 377 automated sequencer with BigDye Terminators (V2.0 and V3.1, Applied Biosystems) and the amplification primers.

Sequences of $m t c y b$ for E. evelynae (80 individuals) were a subset taken from our larger phylogeographic study (Taylor \& Hellberg 2003; GenBank AF543584-AF543591, AF543601-AF543605, AF543613-AF543616, AF543638AF543660, AF543666, AF543669-AF543673, AF543678AF543679). Some $m t c y b$ and rag1 sequences for E. chancei, E. evelynae, E. horsti, E. lori, E. louisae and E. oceanops are a subset taken from our phylogenetic analysis of the genus (Taylor \& Hellberg 2005; GenBank AY846428-AY846431, AY846406-AY846411, AY846413-AY846417, AY846512AY846517, AY846519, AY846521-AY846523, AY846530, AY846533-AY846534, AY846536-AY846537). All other mtcyb and rag1 sequences are presented here for the first time (GenBank DQ250573-DQ250594, DQ255784-DQ255897).

\section{Genetic analyses}

Sequences for each gene region were assembled and edited with SEQUENCHER 3.0, then aligned with CLUSTAL w (www2.ebi.ac.uk/clustalw/) set to default parameters. The haplotype phase for rag1 alleles was independently determined for each nominal species by Bayesian inference with PHASE version 2.1.1 (Stephens et al. 2001; Stephens \& Donnelly 2003). Alternative strategies that applied PHASE to taxa based on discrete mitochondrial lineages (which do not always correspond to named species; Taylor \& Hellberg 2005) did not qualitatively affect haplotype inference for any taxon. Five separate PHASE runs of 100 
iterations each and two further runs of 400 iterations each were performed to ensure convergence of haplotype estimation. Haplotypes for which phase could not be determined with $\geq 60 \%$ confidence were excluded from phylogeographic analyses (Sotka et al. 2004). cOLLAPSE 1.2 (D. Posada, http://darwin.uvigo.es) was used to reduce the data sets of each genetic marker to unique haplotypes within each population for phylogeographic analyses. The resulting data sets for each species were analysed with uncorrected $p$ distances in ARLEQUIN 2.001 (Schneider $e t$ al. 2000). ARLEQUIN was used to perform analyses of molecular variation (Excoffier et al. 1992) and to derive minimumspanning trees to graphically represent inferred genetic connections among the sampled populations. ARLEQUIN was also used to perform Mantel tests to determine whether increased pairwise genetic differentiation between populations correlated with geographic distance. We also employed spatial analysis of molecular variation (sAmova), which defines groups of populations that are geographically close and genetically similar within groups, but maximally differentiated among groups (Dupanloup et al. 2002).

\section{Results}

Aligned sequences were trimmed to exclude ambiguous reads at each end, which yielded 400 base pairs (bp) for $m t c y b$ and $573 \mathrm{bp}$ for rag1 for all individuals. No indels were observed for either marker. Haplotypic phase was unambiguously inferred for rag1 from Elacatinus oceanops. The inferred phase of rag1 alleles for Elacatinus evelynae was unambiguous except for 3 of 80 individuals ( 1 from Jamaica and 2 from the northern Bahamas). Similarly, allele phase could be inferred for rag1 for all but 3 of 83 sponge-dwellers (1 Elacatinus chancei from Grand Turk, and 2 Elacatinus horsti from Grand Cayman and Jamaica). These ambiguous genotypes were excluded from subsequent analyses of nuclear sequences. The number of unique haplotypes for $m t c y b$ and rag1 for each species is detailed in Table 1.

\section{Cleaner species}

Significant genetic structure was evident for E. evelynae (Table 2), with differentiation among island samples accounting for about $80 \%$ of all genetic variation. Geographic distance, however, explained only a modest proportion of the total variance in genetic differentiation among populations at either $m t c y b$ or $r a g 1$ ( $r^{2}=8.5 \%$ and $11.1 \%$, respectively), and genetic differentiation was not significantly correlated with geographic distance (Mantel test, $P>0.05$ ). Individuals from Long Island and the rest of the northern Bahamas shared many haplotypes and alleles, reflected by the absence of genetic structure in the yellow form (data not shown; Taylor \& Hellberg 2003). Thus, the Long Island
Table 2 Comparison of Elacatinus evelynae mtcyb results from this study to results derived from a larger data set (Taylor \& Hellberg 2003)

\begin{tabular}{llll}
\hline & This study & T\&H03sub* & T\&H03all* \\
\hline$N$ & 80 & 189 & 246 \\
No. of populations & 10 & 10 & 17 \\
Distinct haplotypes & $40(50 \%)$ & $64(34 \%)$ & $79(32 \%)$ \\
$\Phi_{\mathrm{ST}}$ & 0.794 & 0.783 & 0.786 \\
$\Phi_{\mathrm{CT}}$ & 0.455 & 0.420 & 0.489 \\
$\Phi_{\mathrm{SC}}$ & 0.622 & 0.627 & 0.580 \\
\hline
\end{tabular}

$\Phi_{\mathrm{ST}}$, proportion of total variation partitioned among island populations; $\Phi_{\mathrm{CT}}$, variation partitioned among the three regions separated by the Mona and Central Bahamas barriers; and $\Phi_{\mathrm{SC}}$ proportion of regional genetic variation distributed among island populations. All $\Phi$ values significant at $P<0.0001$.

*T\&H03sub uses the subset of individuals from Taylor \& Hellberg (2003) sampled from exactly the same populations as in this study. T\&H03all uses all individuals and all populations from Taylor \& Hellberg (2003).

and northern Bahamas populations (all yellow form E. evelynae) were pooled for subsequent analyses. For $m t c y b$ (Fig. 2A), no other haplotypes were shared among populations $\left(\Phi_{\mathrm{ST}}=0.794, P<0.0001\right)$, except for one. Of the three individuals that shared this $m t c y b$ haplotype (Fig. 2A), the two from Grand Turk and Jamaica were both homozygotic for the most abundant rag1 allele, while the northern Bahamas individual was homozygotic for the third most common rag1 allele (Fig. 2B), which suggests retained ancestral polymorphism due to incomplete lineage sorting rather than to recent dispersal. For rag1, two alleles were shared extensively across the Caribbean (Fig. 2B), yet significant genetic structure was evident $\left(\Phi_{\mathrm{ST}}=0.316\right.$, $P<0.0001$ ) due to many population-specific alleles.

Significant $\Phi_{\mathrm{CT}}$ values for $m t c y b$ were obtained for $E$. evelynae between the yellow and blue forms $\left(\Phi_{\mathrm{CT}}=0.630\right.$, $P<0.0001)$ and between the blue and white forms $\left(\Phi_{\mathrm{CT}}=0.140, P<0.0001\right)$, which coincided with the Central Bahamas or Mona Passage barriers, respectively (Fig. 1). The abrupt differentiation within Mona Passage was especially striking because only $23 \mathrm{~km}$ separates Isla Desecheo (white form) from Puerto Rico (blue form). Further, if these two populations were transposed in the AMOva, genetic subdivision vanished $\left(\Phi_{\mathrm{CT}}=0.018, P=0.34\right)$. For rag1, subdivision between the yellow and blue forms (Central Bahamas, $\left.\Phi_{\mathrm{CT}}=0.021\right)$ and between the blue and white forms (Mona Passage, $\Phi_{\mathrm{CT}}=-0.047$ ) was minimal, despite significant genetic structure overall. However, closer examination of rag1 from populations immediately separated by the barriers suggested some disruption of gene flow in the vicinity of the Mona Passage. For example, of 13 distinct rag1 alleles sampled from Isla Desecheo (white form), 10 were unique to this population, and none were 

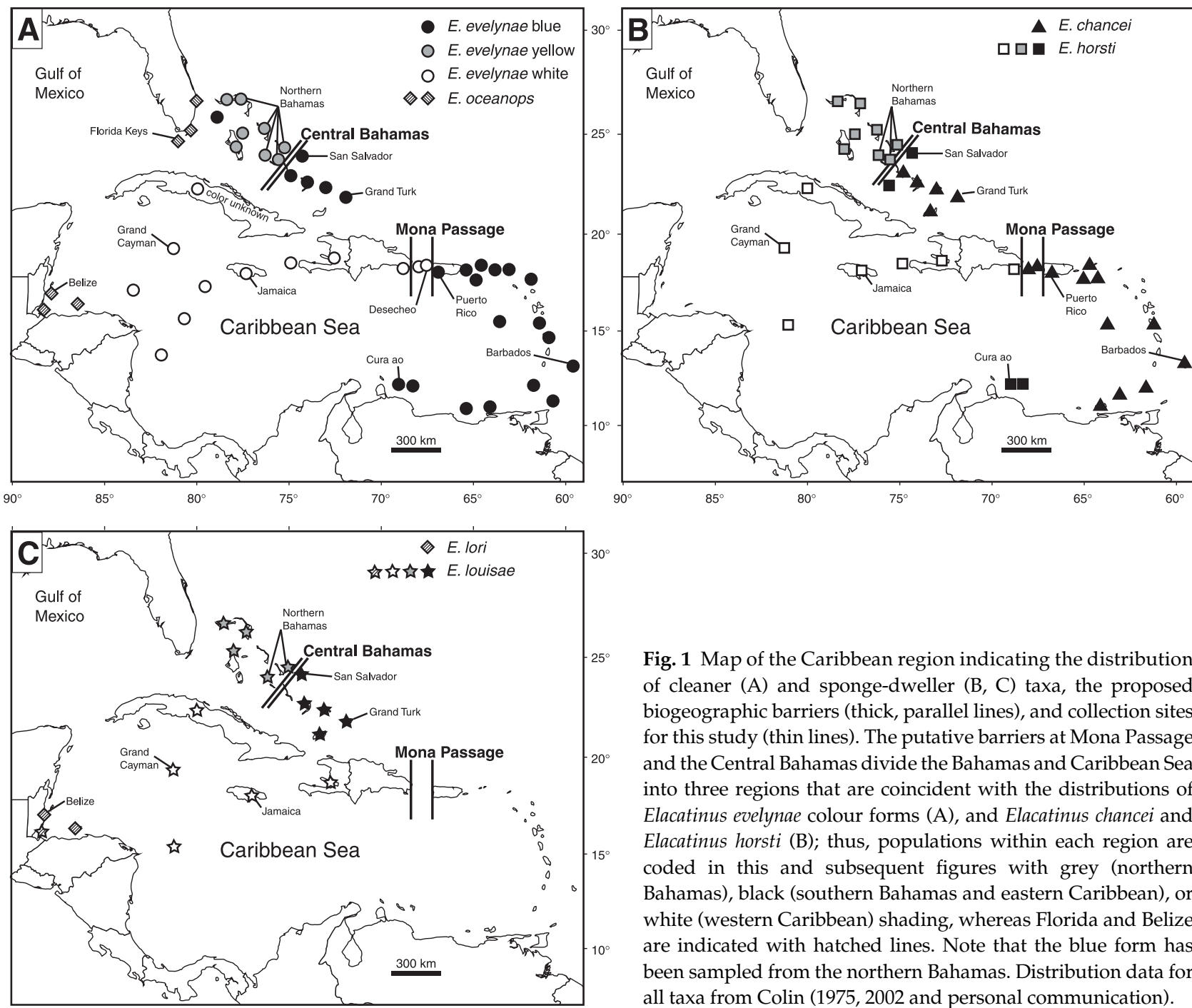

Fig. 1 Map of the Caribbean region indicating the distribution of cleaner (A) and sponge-dweller $(\mathrm{B}, \mathrm{C})$ taxa, the proposed biogeographic barriers (thick, parallel lines), and collection sites for this study (thin lines). The putative barriers at Mona Passage and the Central Bahamas divide the Bahamas and Caribbean Sea into three regions that are coincident with the distributions of Elacatinus evelynae colour forms (A), and Elacatinus chancei and Elacatinus horsti (B); thus, populations within each region are coded in this and subsequent figures with grey (northern Bahamas), black (southern Bahamas and eastern Caribbean), or white (western Caribbean) shading, whereas Florida and Belize are indicated with hatched lines. Note that the blue form has been sampled from the northern Bahamas. Distribution data for all taxa from Colin (1975, 2002 and personal communication).

shared across the intervening $23 \mathrm{~km}$ with Puerto Rico (blue form) (Fig. 2B). The strong genetic structure evident for rag1 between these two populations $\left(\Phi_{\mathrm{ST}}=0.341, P<0.0001\right)$ was comparable to subdivision of rag1 from populations spanning the entire eastern (blue form, $\Phi_{\mathrm{ST}}=0.394$ ) or western (white form, $\Phi_{\mathrm{ST}}=0.293$ ) Caribbean.

Our samova of E. evelynae created groups of geographically close populations that together had the greatest genetic divergence from other population groups (see online supplementary results). For $m t c y b$, the first identified group separated yellow form E. evelynae from the blue and white forms, which supported the closer relationship of this taxon to E. oceanops (Fig. 2). At the level of six groups, Puerto Rico and Isla Desecheo were separated $\left(\Phi_{\mathrm{CT}}=0.650\right.$, $P=0.002)$. More telling was the rag1 analysis, which separated Curaçao, then Isla Desecheo from all other populations, with significant among-group partitions of genetic variation $\left(\Phi_{\mathrm{CT}}=0.295, P=0.025\right)$.
Within E. oceanops, the Florida and Belize populations did not share either $m t c y b$ haplotypes (Fig. 2A; $\Phi_{\mathrm{ST}}=0.810$, $P<0.0001$ ) or rag1 alleles (Fig. $2 \mathrm{~B} ; \Phi_{\mathrm{ST}}=0.737, P<0.0001$ ), which suggested long-term absence of gene flow between these populations. Individuals from these two populations, geographically separated by about $1100 \mathrm{~km}$, had an average $m t c y b$ divergence of about $3 \%(2.5-4.2 \%)$. If a $2 \%$ divergence per million years for $m t c y b$ (Brown et al. 1979) was assumed, a maximum-likelihood analysis using FLUCtUATE (Kuhner et al. 1998) suggested that these two populations had been isolated for roughly 800000 years.

\section{Sponge-dweller species}

Like the cleaners, no $m t c y b$ haplotypes were shared between populations, except for one (Fig. 3A), which explained the strong overall genetic structure within E. chancei (Table 3). Similar results were obtained for rag1: no alleles were 

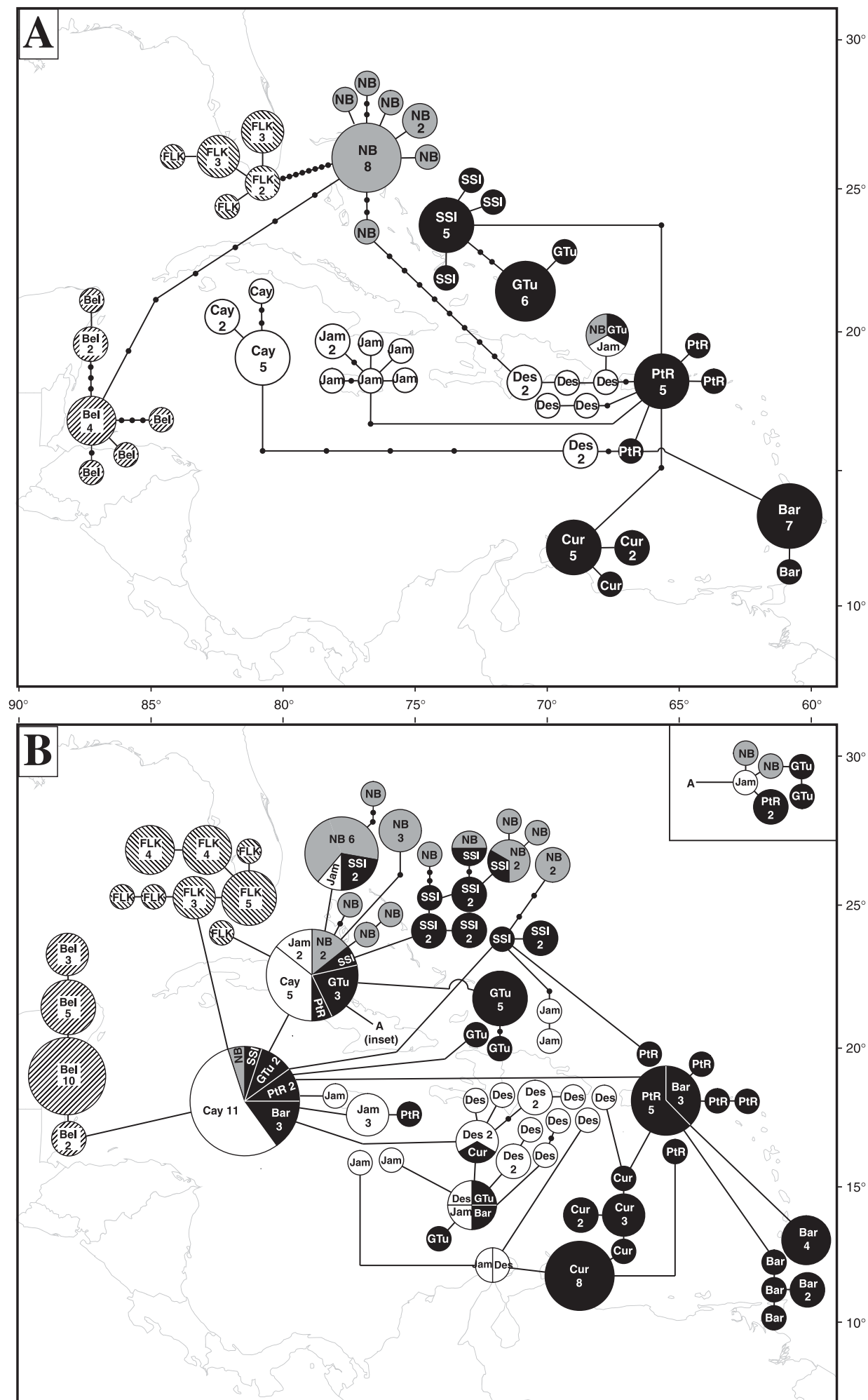

Fig. 2 Minimum-spanning tree inferred for $m t c y b$ (A) and rag1 (B) for cleaner species: Elacatinus oceanops (hatched fill) and Elacatinus evelynae (solid fill). Each unique haplotype or allele is represented by a pie. Pie size is proportional to the total number of individuals with that haplotype or allele; wedges indicate the number of individuals from a population. Small black dots indicate inferred mutational steps between haplotypes or alleles. Shading in the pie charts corresponds to the regions shown in Fig. 1. Bar, Barbados; Bel, Belize; Cay, Grand Cayman; Cur, Curaçao; Des, Isla Desecheo; FLK, Florida Keys; GTu, Grand Turk; Jam, Jamaica; NB, northern Bahamas; PtR, Puerto Rico; SSI, San Salvador Island. 

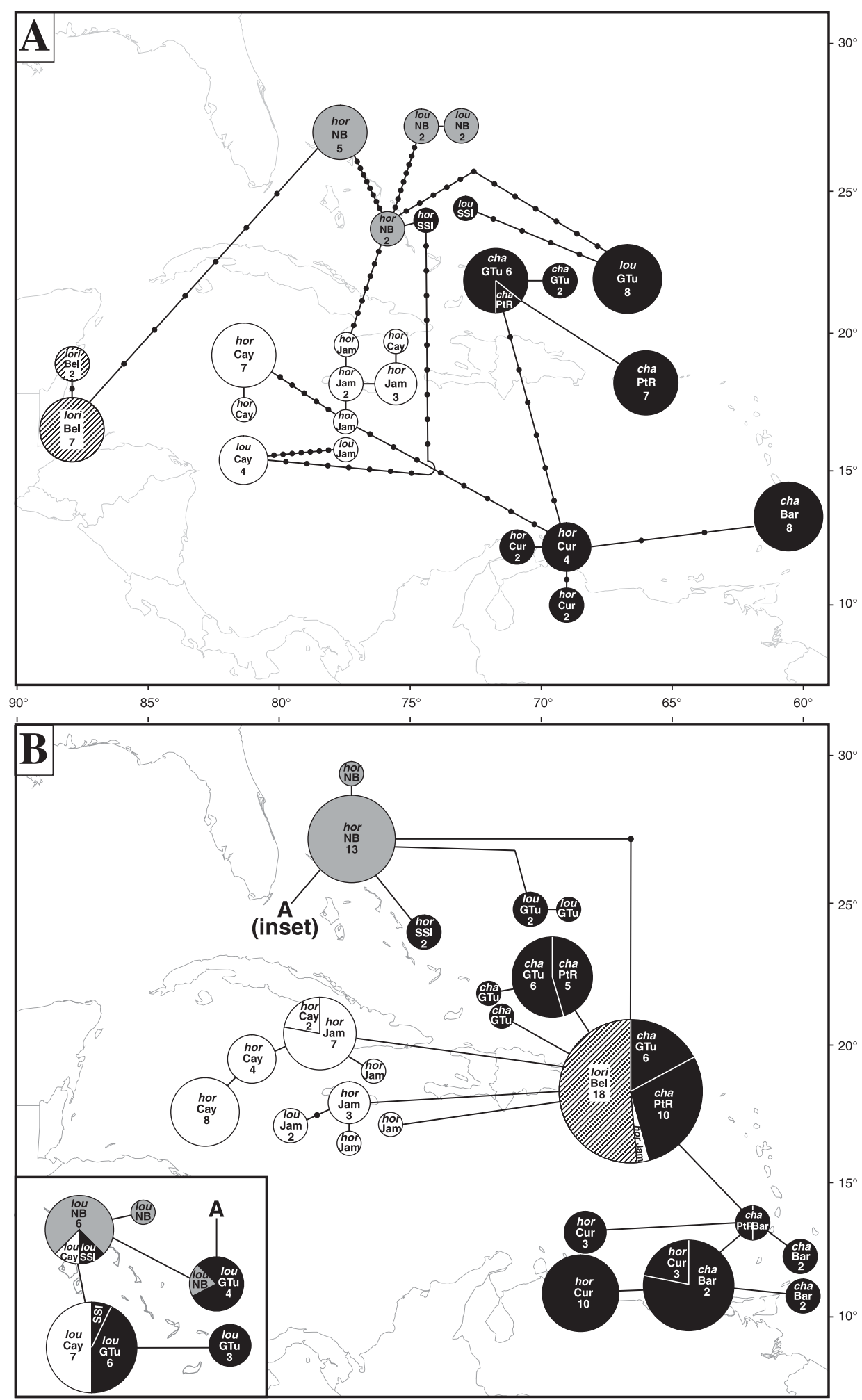

Fig. 3 Minimum-spanning tree inferred for $m t c y b$ (A) and rag1 (B) for sponge-dwelling species: Elacatinus chancei (cha), Elacatinus horsti (hor), Elacatinus lori (lori) and Elacatinus louisae (lou). Each unique haplotype or allele is represented by a pie. Pie size is proportional to the total number of individuals with that haplotype or allele; wedges indicate the number of individuals from a population. Small black dots indicate inferred mutational steps between haplotypes or alleles. Shading in the pie charts corresponds to the regions shown in Fig. 1. Bar, Barbados; Bel, Belize; Cay, Grand Cayman; Cur, Curaçao; GTu, Grand Turk; Jam, Jamaica; NB, northern Bahamas; PtR, Puerto Rico; SSI, San Salvador Island. 
Table 3 Proportion of total variation partitioned among island populations $\left(\Phi_{\mathrm{ST}}\right)$ for sponge-dwelling Elacatinus.

\begin{tabular}{lcc}
\hline & $m t c y b$ & rag1 \\
\hline E. chancei & 0.963 & 0.590 \\
E. horsti & 0.833 & 0.807 \\
E. louise & 0.922 & 0.399 \\
E. chancei + Curaçao & 0.921 & 0.669 \\
E. horsti-Curaçao & 0.804 & 0.761 \\
\hline
\end{tabular}

All values significant at $P<0.0001$. Last two rows pool Elacatinus horsti from Curaçao with Elacatinus chancei (see Fig. 1 and text for details).

found in more than three populations, most alleles were sampled from only one or two populations (Fig. 3B), and subdivision was high (Table 3 ). The minimum-spanning trees obtained here (Fig. 3) suggested that E. horsti from Curaçao is more closely related to E. chancei than to other $E$. horsti, in agreement with previous phylogenetic analyses (Taylor \& Hellberg 2005). However, genetic structure remains high when Curaçao E. horsti was pooled with E. chancei (Table 3).

Figure $3 \mathrm{~A}$ shows that one mtcyb haplotype sampled from two E. horsti from Long Island in the northern Bahamas was only one step removed from a haplotype sampled from San Salvador, but nine steps removed from other northern Bahamas haplotypes. However, the Long Island individuals had the same rag1 alleles as all other northern Bahamas E. horsti, while the San Salvador individuals had unique alleles, which may reflect exchange of $m t c y b$ between the colour forms across the Central Bahamas barrier.

\section{Sample size and geographic variation}

To assess whether sample size influenced our results, we compared the E. evelynae mtcyb results obtained in this study to a larger $m t c y b$ survey of this species (Taylor \& Hellberg 2003). Our previous study sampled both a greater number of individuals of E. evelynae ( 246 vs. 80 here) and more populations (17 vs. 10). Estimates of genetic subdivision obtained in this study were close to those from our more comprehensive survey (Table 2). We also tested for geographic heterogeneity of haplotype and allele frequencies by Monte Carlo simulations (Roff \& Bentzen 1989) with the REAP software package (McElroy et al. 1992), and with exact tests of population differentiation (Raymond \& Rousset 1995) implemented in ARLEQUIN (10 000 Markov chain steps). Both tests, which are unbiased by small sample sizes (Raymond \& Rousset 1995), indicated significant heterogeneity $(P<0.001)$ of allele and haplotype frequencies among populations of all species studies here (see online supplementary results).
Finally, we assumed complete admixture of genes for E. evelynae between Puerto Rico and Isla Desecheo, and pooled our samples from these two populations to determine relative gene frequencies. These frequencies were then used in binomial analyses to determine the probability of not sampling any genes represented in one population (e.g. Isla Desecheo) in a sample of 16 (or 8) genes from the other population (e.g. Puerto Rico). Although the probability of not sampling the most common gene is approximately 0.35 , the probability of not sampling any gene from the other population is $P=0.000015$ for rag1 and $P=0.004$ for $m t c y b$ (complete analyses available online). Thus, while modest sample sizes, including ours, must always be interpreted with caution, these analyses suggest that our samples have adequately captured the natural genetic variation of the populations and taxa studied here.

\section{Discussion}

We tested whether two previously proposed Caribbean biogeographic barriers, hypothesized from the distribution of several reef fishes (Colin 1975; Starck \& Colin 1978; Colin et al. 2003; Dennis et al. 2004), imposed a barrier to genetic exchange within two ecologically distinct clades of the genus Elacatinus. The results of our study employing two independent genetic markers indicated that multiple monophyletic lineages have evolved within several species of Elacatinus, and that these lineages did not always correspond with current taxonomy. Instead, these lineages generally corresponded to one of three geographic areas within the Caribbean region (Fig. 1). These three regions are separated by biogeographic breaks that were previously postulated based on current patterns and the distributions of species and colour forms of reef fishes (Colin 1975, 1995; Colin et al. 2003). Furthermore, the northern Bahamas taxa appeared to be more closely related to species from the Gulf of Honduras than to those from elsewhere in the Caribbean (Figs 2 and 3).

\section{Mona Passage}

Our earlier work (Taylor \& Hellberg 2003) provided the first genetic support for the presence of a barrier to gene flow near the Mona Passage. This break separated mtcyb lineages of Elacatinus evelynae (Fig. 2A), with the most striking result being the lack of shared $m t c y b$ haplotypes between Puerto Rico and Isla Desecheo, islands that are separated by only $23 \mathrm{~km}$ (Taylor \& Hellberg 2003). Our new rag1 data for E. evelynae further supported the absence of ongoing gene flow across this barrier. Only two rag1 alleles occurred widely across the Caribbean, and these alleles occupied a central position in the minimum-spanning tree (Fig. 2B). In comparison, the eastern and western Caribbean regions harboured a diversity of private derived 
alleles. Further, as with mtcyb, Puerto Rico and Isla Desecheo were genealogically close, but no alleles were shared between them despite the short intervening distance. This close phylogeographic relationship, coupled with unshared derived alleles, suggested that disruption of gene flow across Mona Passage was relatively recent, with some ancestral alleles retained in each region from ongoing lineage sorting (Avise 2000).

In addition to strengthening our previous observations for the parasite-cleaning E. evelynae, our new data also supported a coincident break at Mona Passage for a lineage of sponge-dwellers (Fig. 3). The nominal forms of two species from this lineage, Elacatinus chancei and Elacatinus horsti, generally coincided with observed genetic discontinuities around the Mona Passage. The exception was E. horsti from Curaçao, which appeared to be more closely related to E. chancei, also from the eastern Caribbean. Regardless of taxonomic status, no mtcyb haplotypes or rag1 alleles were shared across the Mona Passage.

Instead of a biogeographic break at Mona Passage, the boundary between colour forms of E. evelynae, a cleaner goby, may be maintained by host fishes imposing selective pressure based on the cleaner goby's lateral stripe colour (Palumbi \& Warner 2003; Rocha et al. 2005). However, as shown here, sponge-dwelling gobies also had phylogeographic breaks associated with Mona Passage, which should not be constrained by selection for lateral stripe colour (Taylor \& Hellberg 2005). Further, host fishes do not apparently distinguish between differently coloured, co-occurring cleaners (Colin 1975; Whiteman \& Côté 2002). Thus, we consider a biogeographic break rather than selection imposed by host fishes to be the more likely explanation for the coincident boundaries of the species studied here.

The distribution of Caribbean fishes other than Elacatinus may also be influenced by the Mona Passage. Species not extending east of the passage include the serranids Gramma melacara (Starck \& Colin 1978; Colin et al. 2003), Hypoplectrus gummigutta, and Hypoplectrus providencialis (Domeier 1994). Species as diverse as a tonguesole, Symphurus arawak (Munroe 1998), and a pipefish, Anarchopterus tectus (Dawson \& Vari 1982), are more common west of the passage than to the east, while another Caribbean pipefish, Syngnathus dawsoni, occurs only east of the passage (Dawson \& Vari 1982). The widespread clinid fish, Malacoctenus triangulatus, shows distinct morphometric differences between individuals sampled across this region (Springer \& Gomon 1975). All of these species, along with the cleaner and sponge-dweller Elacatinus species studied here, occupy very different habitats, which suggests that the distribution of these species is not determined by ecological differences across the Mona Passage.

Our evidence suggests that a biogeographic barrier exists in the vicinity of Mona Passage, but the mechanism underlying this break is unclear. Coral reefs separated by Mona Passage are generally similar in water temperature, clarity, and depth. Water depth in Mona Passage is not more than $1000 \mathrm{~m}$, yet this passage separates colour forms of E. evelynae, and marks the range boundary between $E$. horsti and E. chancei. In contrast, individuals of white form E. evelynae sampled from Jamaica and Navassa, separated by approximately $250 \mathrm{~km}$ and water depths approaching $3000 \mathrm{~m}$, were genetically identical (Taylor \& Hellberg 2003). However, moderate to strong water current can function as an impenetrable or semipermeable barrier to dispersal, even with identical habitat to either side of the current (Gaylord \& Gaines 2000). Strong currents and complex eddies characterize water flow through Mona Passage (Caribbean Fishery Management Council 1999), so this mechanism may serve to isolate populations from either side of the passage for some reef fishes. This is consistent with larval dispersal models which show that larvae released at St Croix (east of Puerto Rico) were generally unable to disperse west of Puerto Rico (Cowen et al. 2003).

The break at the Mona Passage extends to at least one nonteleost species as well, featuring in the genetic structure of Acropora palmata, a reef-building coral whose larvae develop in the plankton for about 1 week. Multilocus genotyping revealed a genetic divide in the region of Puerto Rico and the Mona Passage that separated populations in the western and eastern Caribbean (Baums et al. 2005). The coincident genetic divergence for a coral and several fish species, coupled with distributional limitations and morphological changes for many ecologically diverse fishes, together provide strong evidence for the presence of a biogeographic barrier in the region of the Mona Passage.

However, the Mona Passage apparently imposes different constraints on different taxa. For example, of the species studied here, the blue form of E. evelynae is found from Puerto Rico and eastward, while the white form of E. evelynae is found from Isla Desecheo westward (Colin 1975). Isla Desecheo lies within the Mona Passage, only $23 \mathrm{~km}$ off the western coast of Puerto Rico. In contrast, E. chancei has a distribution that is nearly identical to the blue form of E. evelynae, but extends at least as far as Isla Mona in the middle of Mona Passage, and is then replaced by E. horsti from Hispaniola westward (Colin 1975) (Fig. 1). Similarly, the hamlets Hypoplectrus indigo and Hypoplectrus aberrans apparently range from the western Caribbean eastward to the Puerto Rican plateau but no farther (Domeier 1994; Dennis et al. 2004). Thus, while Mona Passage may function as a biogeographic barrier for the species of Elacatinus studied here, as well as for some other reef fishes (Colin et al. 2003), the 'Mona barrier' may actually encompass the region of Mona Passage and the Puerto Rican plateau. 


\section{Central Bahamas}

Another biogeographic break may be present in the central Bahamas, but our results were less conclusive than for the Mona Passage. The central Bahamas, near the southern end of Exuma Sound and Long Island, is where the ranges of the yellow and blue forms of E. evelynae adjoin (Colin 1975). Our earlier work demonstrated a large genetic gap (3.0\% for $m t c y b$ ) between these forms (Taylor \& Hellberg 2003) that was coincident with this break, but our results here suggested that yellow form E. evelynae was more closely related to Elacatinus oceanops than to the other colour forms of E. evelynae (Fig. 2). Similarly, the Central Bahamas barrier did not genetically divide sister groups for most sponge-dwelling taxa, but instead coincided with distributional boundaries of more distantly related taxa.

Genetic support for the break did come from one spongedweller, Elacatinus louisae (Fig. 3), a species distributed throughout the Bahaman archipelago (Colin 1975). Although the sample size was small, our mtcyb and rag1 results suggested that populations of E. louisae from the southern Bahamas were genetically distinct from northern Bahamas populations (Fig. 3); however, greater sampling would be required to explore this pattern in detail. Increased sampling would also be necessary to better understand gene flow across this region for E. horsti. The mtcyb and rag1 results together suggested that $E$. horsti from San Salvador was genetically divergent from other northern Bahamas populations (Fig. 3), but possible exchange of $m t c y b$ from San Salvador across the barrier to Long Island (see Results) suggested at least intermittent gene flow.

Colin $(1975,1995)$ speculated that the Central Bahamas barrier resulted from the combined effects of lowered sea levels during the Pleistocene that initially isolated populations in Exuma Sound, and ongoing current flows that maintained larvae in the vicinity of Exuma Sound. The current gyres within Exuma Sound may have led to genetic differentiation between Exuma Sound and San Salvador populations of Pseudopterogoria elisbethae, a gorgonian coral (Gutiérrez-Rodríguez \& Lasker 2004). Similarly in Elacati$n u s$, a combination of current flow, limited larval dispersal, and sea level fluctuations may have led to isolation and speciation (e.g. for Elacatinus atronasus), or genetic differentiation (e.g. for yellow forms of E. evelynae and E. horsti from the northern Bahamas) (Colin 1975, 1995; Taylor \& Hellberg 2003, 2005). However, although neither yellow form E. evelynae nor northern Bahamas E. horsti cross the Central Bahamas barrier, both taxa appear to be more closely related to species from Florida or Belize and not to a species in the southern Bahamas (Figs 2 and 3), which suggests that primary genetic divergence of these taxa was minimally influenced by a Central Bahamas barrier. In total, the lack of clear genetic evidence for a Central Bahamas barrier suggests that, if present, this break may be weaker or have developed more recently than the Mona Passage.

\section{Geography and speciation in Elacatinus}

The Gobiidae, which includes Elacatinus, is the largest constituent of Neotropical reef fishes (Robertson 1998). This wealth of goby diversity may stem more from ancestral ecological and behavioural diversification, rather than biogeography (Rüber et al. 2003). However, geographic isolation may also be an important component of goby evolution because, at least in Elacatinus, many sister taxa have allopatric distributions (Taylor \& Hellberg 2005) that coincide with the putative biogeographic barriers studied here. Despite this coincidence, the deepest genetic splits associated with $m t c y b$ and rag1 did not coincide with the two proposed geographic barriers (Figs 2 and 3). This suggests that the barriers were not directly responsible for the initial isolation of populations between the different regions (e.g. eastern and western Caribbean). Instead, our results suggest that ongoing gene flow between regions was limited or prevented by the proposed barriers. These barriers, especially when coupled with larval retention at natal populations (Taylor \& Hellberg 2003), may sufficiently isolate populations and facilitate rapid adaptation to local ecological conditions (Warner 1997; Grosberg \& Cunningham 2000; Rüber et al. 2003).

\section{The northwestern Caribbean}

The northwestern Caribbean region spans from the Gulf of Honduras to the Bahamas, and harbours a number of endemic species (Roberts et al. 2002). A phylogeographic connection between the Gulf of Honduras and the Bahamas was evident in both the cleaner and sponge-dweller clades. For cleaners, the relationship of E. oceanops and yellow form E. evelynae for both genetic markers supported a northwestern Caribbean tract (Fig. 2), but for spongedwellers the $m t c y b$ and rag 1 data yielded conflicting results. For rag1, a Gulf of Honduras/eastern Caribbean connection was implied: Elacatinus lori, a Gulf of Honduras endemic, shared a single rag1 allele with one individual of Jamaican $E$. horsti and with numerous individuals of $E$. chancei from Puerto Rico and Grand Turk (Fig. 3B). For $m t c y b$, however, a relationship between $E$. lori and northern Bahamas E. horsti was supported (Fig. 3A), which mirrors the phylogeographic connection between the cleaner species. When this northwestern Caribbean/Bahamas tract is considered along with the extremely low allelic diversity of rag1 for E. lori (all individuals were homozygous for the same allele), we think that the shared rag1 allele between Belize and the eastern Caribbean most likely results from lineage sorting.

Although our results provided genetic evidence for a northwestern Caribbean tract, genetic divergence within 
this region was evident for both cleaner and spongedweller species (Figs 2 and 3). Most notable was E. oceanops, which was reciprocally monophyletic between Belize and Florida for $m t c y b$ and nearly so for rag1 (Fig. 2). This isolation over evolutionary time scales (roughly 800000 years; see Results) may be facilitated by the apparent absence of intervening populations in Cuba (Colin 1975; R. Claro, personal communication) and by local larval retention (Taylor \& Hellberg 2003). Local retention of pelagic larvae in the Gulf of Honduras, due possibly to current gyres (Colin 2002), may explain not only the isolation of E. oceanops, but also the endemism of several other reef fishes in this region (e.g. Collette 1974; Johnson \& Brothers 1989; Colin 2002).

The geographic restriction of many reef fishes, including other species of Elacatinus not studied here (Colin 1975; Taylor \& Hellberg 2005), to the northwestern Caribbean shows striking parallels to some freshwater and terrestrial vertebrates. Species as different as poeciliid fishes (Briggs 1984; Rauchenberger 1988) and anoline lizards (Guyer \& Savage 1986; Losos et al. 1998) show considerable diversity that extends from Central America, across the Greater Antilles, and into the Bahamas, but are absent or present at reduced diversity across the Lesser Antilles. This pattern is all the more striking due to the vastly different evolutionary ages of these groups: at least some lineages within Elacatinus likely split due to Pleistocene sea level fluctuations (Colin 1975), while divergences among anoline lizards in the Greater Antilles can date back to at least 20-33 million years ago (Polcyn et al. 2002).

\section{Summary}

Historical barriers to gene flow are sometimes inferred from a single mitochondrial marker from a single taxon, but such inferences may be problematic (Neigel \& Avise 1993; Irwin 2002). Our study of biogeographic breaks in the Caribbean avoided such problems in three ways. First, we used two independent genetic markers, one mitochondrial $(m t c y b)$ and one nuclear (rag1). Second, we used nine taxa from two evolutionarily independent lineages with different feeding and habitat requirements. Finally, the biogeographic breaks that we tested, the Mona Passage and the Central Bahamas, were hypothesized a priori (Colin 1995; Colin et al. 2003). Our results supported the presence of a biogeographic break at the Mona Passage, but were less conclusive for a similar break in the central Bahamas. The phylogeographic structure revealed by our study at times conflicted with existing taxonomic nomenclature, and instead suggested a division between the northwestern Caribbean, encompassing Belize, parts of the Greater Antilles and the northern Bahamas, and a southeastern region across the rest of the Caribbean. Within each region, subsequent genetic division has generated several monophyletic lineages, especially for $m t c y b$, and near reciprocal monophyly of rag1 between Florida and Belize was evident for one species. In total, the presence of multiple, geographically distinct lineages in the taxa studied here suggests a propensity in this genus for genetic subdivision to evolve. Current geographic structure may mirror past phylogeographic history and help to explain the richness of Elacatinus in the Caribbean.

\section{Acknowledgements}

We thank S. L. Taylor, J. Van Tassell, T. Austin, R. Bishop, K. Cheney, I. Côté, M. Day, R. Eytan, E. Haley and Sunset Divers Grand Cayman, S. Macia, W. O. McMillan, J. Pawlik, M. Robinson, D. Schrier and the staff of the Curaçao Sea Aquarium, C. Van Buuren, W. Von Lubbe, E. Whiteman, R/V Seward Johnson, R/V Sea Diver, and the Government of the Bahamas for assistance with obtaining specimens; H. Griffith, N. Crochet, P. Arbour-Reily, A. Ardouin, J. Huff and E. Penedo for technical assistance; and P. Colin for access to his unpublished distribution data and for general discussions on Elacatinus. Supported by grants from the American Museum of Natural History, the American Society of Ichthyology and Herpetology, and Sigma Xi (Louisiana State University Chapter) to M.S.T., and National Science Foundation grants to M.E.H. (DEB-0075382), to M.S.T. (Doctoral Dissertation Improvement Grant, DEB-0206632), and to the LSU Museum of Natural Sciences (NSF Multiuser Equipment Grant DBI-0400797).

\section{Supplementary materials}

The supplementary material is available from http://www.blackwellpublishing.com/products/journals / suppmat/MEC/MEC2820/MEC2820sm.htm

\section{References}

Acero PA (1985) Zoological implications of the distribution of selected families of Caribbean coral reef fishes. Proceedings of the Fifth International Coral Reef Congress, Tahiti, 5, 433-438.

Avise JC (2000) Phylogeography. The History and Formation of Species. Harvard University Press, Cambridge, Massachusetts.

Barraclough TG, Vogler AP (2000) Detecting the geographical pattern of speciation from species-level phylogenies. American Naturalist, 155, 419-434.

Baums IB, Miller MW, Hellberg ME (2005) Regionally isolated populations of an imperiled Caribbean coral, Acropora palmata. Molecular Ecology, 14, 1377-1390.

Birky CW Jr, Maruyama T, Fuerst PA (1983) An approach to population and evolutionary genetic theory for genes in mitochondria and chloroplasts, and some results. Genetics, 103, 513-527.

Birky CW Jr, Fuerst PA, Maruyama T (1989) Organelle gene diversity under migration, mutation, and drift: equilibrium expectations, approach to equilibrium, effects of heteroplasmic cells, and comparison to nuclear genes. Genetics, 121, 613-627.

Böhlke JE, Robins CR (1960) Western Atlantic gobioid fishes of the genus Lythrypnus, with notes on Quisquilius hipoliti and Garmannia pallens. Proceedings of the Academy of Natural Sciences of Philadelphia, 112, 73-101.

Böhlke JE, Robins CR (1968) Western Atlantic seven-spined gobies, with descriptions of ten new species and a new genus, 
and comments on Pacific relatives. Proceedings of the Academy of Natural Sciences of Philadelphia, 120, 45-174.

Böhlke JE, Springer VG (1961) A review of the Atlantic species of the clinid fish genus Starksia. Proceedings of the Academy of Natural Sciences of Philadelphia, 113, 29-60.

Briggs JC (1974) Marine Zoogeography. McGraw-Hill Co, New York.

Briggs JC (1984) Freshwater fishes and biogeography of Central America and the Antilles. Systematic Zoology, 33, 428-435.

Brown WM, George M Jr, Wilson AC (1979) Rapid evolution of animal mitochondrial DNA. Proceedings of the National Academy of Science, USA, 76, 1967-1971.

Colin PL (1975) Neon Gobies. T.F.H. Publications, Inc, Neptune City, New Jersey.

Colin PL (1995) Surface currents in Exuma Sound, Bahamas and adjacent areas with reference to potential larval transport. Bulletin of Marine Science, 56, 48-57.

Colin PL (2002) A new species of sponge-dwelling Elacatinus (Pisces: Gobiidae) from the western Caribbean. Zootaxa, 106, 17.

Colin PL, Taylor MS, Hellberg ME, Warner RR, Palumbi SR (2003) Larvae retention: genes or oceanography? Science, 300, 16571657.

Collette BB (1974) A review of the coral toadfishes of the genus Sanopus with descriptions of two new species from Cozumel Island, Mexico. Proceedings of the Biological Society of Washington, 87, 185-204.

Caribbean Fishery Management Council (1999) Essential fish habitat descriptions for Caribbean fishery management plans San Juan, Puerto Rico. CFMC, San Juan, Puerto Rico. www.nmfs.noaa.gov/ habitat/habitatprotection/profile/caribbean.htm.

Cowen RK, Paris CB, Olson DB, Fortuna JL (2003) The role of long distance dispersal versus local retention in replenishing marine populations. Journal of Gulf and Caribbean Research, 14, 129-138.

Dawson CE, Vari RP (1982) Fishes of the Western North Atlantic. Part Eight, Order Gasterosteiformes, Suborder Syngnathoidei, Family Syngnathidae. Sears Foundation for Marine Research, Yale University, New Haven, Connecticut.

Dennis GD, Hensley D, Colin PL, Kimmel JJ (2004) New records of marine fishes from the Puerto Rican Plateau. Caribbean Journal of Science, 40, 70-87.

Domeier ML (1994) Speciation in the serranid fish Hypoplectrus. Bulletin of Marine Science, 54, 103-141.

Dupanloup I, Schneider S, Excoffier L (2002) A simulated annealing approach to define the genetic structure of populations. Molecular Ecology, 11, 2571-2581.

Excoffier L, Smouse PE, Quattro JM (1992) Analysis of molecular variance inferred from metric distances among DNA haplotypes: application to human mitochondrial DNA restriction data. Genetics, 131, 479-491.

Gaylord B, Gaines SD (2000) Temperature or transport? Range limits in marine species mediated solely by flow. American Naturalist, 155, 769-789.

Greenfield DW (1979) A review of the western Atlantic Starksia ocellata-complex (Pisces: Clinidae) with the description of two new species and proposal of superspecies status. Fieldiana Zoo$\log y, 73,9-47$.

Grosberg R, Cunningham CW (2000) Genetic Structure in the Sea: From Populations to Communities. Sinauer Associates, Sunderland, Massachusetts.

Gutiérrez-Rodríguez C, Lasker HR (2004) Microsatellite variation reveals high levels of genetic variability and population struc- ture in the gorgonian coral Pseudopterogorgia elisabethae across the Bahamas. Molecular Ecology, 13, 2211-2221.

Guyer C, Savage JM (1986) Cladistic relationships among anoles (Sauria: Iguanidae). Systematic Zoology, 35, 509-531.

Hastings PA (2000) Biogeography of the tropical eastern Pacific: distribution and phylogeny of chaenopsid fishes. Zoological Journal of the Linnean Society, 128, 319-335.

Irwin DE (2002) Phylogeographic breaks without geographic barriers to gene flow. Evolution, 56, 2383-2394.

Johnson GD, Brothers EB (1989) Acanthemblemaria paula, a new diminutive chaenopsid (Pisces, Blennioidei) from Belize, with comments on life history. Proceedings of the Biological Society of Washington, 102, 1018-1030.

Kuhner MK, Yamato J, Felsenstein J (1998) Maximum likelihood estimation of population growth rates based on the coalescent. Genetics, 149, 429-434.

Losos JB, Jackman TR, Larson A, de Queiroz K, Rodríguez Schettino L (1998) Contingency and determination in replicated adaptive radiations of island lizards. Science, 279, 2115-2118.

Malfait BT, Dinkelman MG (1972) Circum-Caribbean tectonic and igneous activity and the evolution of the Caribbean plate. Geological Society of America Bulletin, 83, 251-272.

Mayr E (1954) Geographic speciation in tropical echinoids. Evolution, 8, 1-18.

McElroy D, Moran P, Bermingham E, Kornfield I (1992) REAP: an integrated environment for the manipulation and phylogenetic analysis of restriction data. Journal of Heredity, 83, 157-158.

Morrison CL, Rios R, Duffy JE (2004) Phylogenetic evidence for an ancient rapid radiation of Caribbean sponge-dwelling snapping shrimps (Synalpheus). Molecular Phylogenetics and Evolution, 30, 563-581.

Munroe TA (1998) Systematics and ecology of tonguefishes of the genus Symphurus (Cynoglossidae: Plueronectiformes) from the western Atlantic Ocean. Fishery Bulletin, 96, 1-182.

Neigel JE, Avise JC (1993) Application of a random walk model to geographic distributions of animal mitochondrial DNA variation. Genetics, 135, 1209-1220.

Palumbi SR (1996) Nucleic acids II: the polymerase chain reaction. In: Molecular Systematics (eds Hillis DM, Moritz C, Mable BK), pp. 205-247. Sinauer Associates, Sunderland, Massachusetts.

Palumbi SR, Warner RR (2003) Why gobies are like hobbits. Science, 299, 51-52.

Pindell JL, Barrett SF (1990) Geological evolution of the Caribbean region; a plate-tectonic perspective. In: The Caribbean Region (eds Dengo G, Case JE), pp. 405-432. Geological Society of America, Boulder, Colorado.

Polcyn MJ, Rogers JV II, Kobayashi Y, Jacobs LL (2002) Computed tomography of an anolis lizard in Dominican amber: systematic, taphonomic, biogeographic, and evolutionary implications. Palaeontologia Electronica, 5, 1-13.

Rauchenberger M (1988) Historical biogeography of poeciliid fishes in the Caribbean. Systematic Zoology, 37, 356-365.

Raymond M, Rousset F (1995) An exact test for population differentiation. Evolution, 49, 1280-1283.

Roberts CM, McClean CJ, Veron JEN et al. (2002) Marine biodiversity hotspots and conservation priorities for tropical reefs. Science, 295, 1280-1284.

Robertson DR (1998) Do coral-reef fish faunas have a distinctive taxonomic structure? Coral Reefs, 17, 179-186.

Rocha LA (2003) Patterns of distribution and processes of speciation in Brazilian reef fishes. Journal of Biogeography, 30, 1161-1171. 
Rocha LA, Bass AL, Robertson DR, Bowen BW (2002) Adult habitat preferences, larval dispersal, and the comparative phylogeography of three Atlantic surgeonfishes (Teleostei: Acanthuridae). Molecular Ecology, 11, 243-252.

Rocha LA, Robertson DR, Roman J, Bowen BW (2005) Ecological speciation in tropical reef fishes. Proceedings of the Royal Society of London. Series B, Biological Sciences, 272, 573-579.

Roff DA, Bentzen P (1989) The statistical analysis of mitochondrial DNA polymorphisms: $\chi^{2}$ and the problem of small samples. Molecular Biology and Evolution, 6, 539-545.

Rüber L, Van Tassell JL, Zardoya R (2003) Rapid speciation and ecological divergence in the American seven-spined gobies (Gobiidae, Gobiosomatini) inferred from a molecular phylogeny. Evolution, 57, 1584-1598.

Schneider S, Roessli D, Excoffier L (2000) ARLEQUIN: A software for population genetics data analysis. Version 2.000. Genetics and Biometry Laboratory, Department of Anthropology. University of Geneva, Switzerland.

Shulman MJ, Bermingham E (1995) Early life histories, ocean currents, and the population genetics of Caribbean reef fishes. Evolution, 49, 897-910.

Sotka EK, Wares JP, Barth JA, Grosberg RK, Palumbi SR (2004) Strong genetic clines and geographical variation in gene flow in the rocky intertidal barnacle Balanus glandula. Molecular Ecology, 13, 2143-2156.

Springer VG, Gomon MF (1975) Variation in the western Atlantic clinid fish Malacoctenus triangulatus with a revised key to the Atlantic species of Malacoctenus. Smithsonian Contributions to Zoology, 200, 1-11.

Starck WA II, Colin PL (1978) Gramma linki: a new species of grammid fish from the tropical western Atlantic. Bulletin of Marine Science, 28, 146-152.
Stephens M, Donnelly P (2003) A comparison of Bayesian methods for haplotype reconstruction from population genotype data. American Journal of Human Genetics, 73, 1162-1169.

Stephens M, Smith NJ, Donnelly P (2001) A new statistical method for haplotype reconstruction from population data. American Journal of Human Genetics, 68, 978-989.

Taylor MS, Hellberg ME (2003) Genetic evidence for local retention of pelagic larvae in a Caribbean reef fish. Science, 299, 107-109.

Taylor MS, Hellberg ME (2005) Marine radiations at small geographic scales: speciation in Neotropical reef gobies (Elacatinus). Evolution, 59, 374-385.

Warner RR (1997) Evolutionary ecology: how to reconcile pelagic dispersal with local adaptation. Coral Reefs, 16, S115-S120.

Whiteman EA, Côté IM (2002) Cleaning activity of two Caribbean cleaning gobies: intra- and interspecific comparisons. Journal of Fish Biology, 60, 1443-1458.

Wiens JJ (2004) What is speciation and how should we study it? American Naturalist, 163, 914-923.

Williams JT, Mounts JH (2003) Descriptions of six new Caribbean fish species in the genus Starksia (Labrisomidae). Aqua, Journal of Ichthyology and Aquatic Biology, 6, 145-164.

M.S.T. did his PhD work on speciation and phylogeography of Elacatinus. His primary focus is on genetical and ecological mechanisms underlying population divergence and speciation of reef fishes, but is currently studying the genetics of host odor recognition in Rhagoletis flies. M.E.H. is an associate professor at Louisiana State University. He has broad interests in phylogeography, speciation, and molecular evolution, especially in corals, marine gastropods, and reef fishes. 